\title{
Individual and contextual factors associated with under- and over-nutrition among school-aged children and adolescents in two Nigerian states: a multi-level analysis
}

\author{
Adeleye Abiodun Adeomi ${ }^{1,2, *}{ }^{(10}$, Adesegun Fatusi ${ }^{1,3}$ and Kerstin Klipstein-Grobusch ${ }^{2,4}$ \\ 'Department of Community Health, College of Health Sciences, Obafemi Awolowo University, lle-lfe, Osun, Nigeria: \\ ${ }^{2}$ Division of Epidemiology and Biostatistics, School of Public Health, Faculty of Health Sciences, University of the \\ Witwatersrand, Johannesburg, South Africa: ${ }^{3}$ Centre for Adolescent Health and Development, School of Public Health, \\ University of Medical Sciences, Ondo, Nigeria: ${ }^{4}$ Julius Global Health, Julius Center for Health Sciences and Primary \\ Care, University Medical Center Utrecht, Utrecht University, The Netherlands
}

Submitted 9 August 2021: Final revision received 22 December 2021: Accepted 21 January 2022: First published online 24 January 2022

\begin{abstract}
Objective: This study aimed to identify individual and contextual factors that are associated with under- and over-nutrition among school-aged children and adolescents in two Nigerian states.

Design: Community-based cross-sectional study.

Setting: The study was carried out in rural and urban communities of Osun and Gombe States in Nigeria.

Participants: A total of 1200 school-aged children and adolescents.

Results: Multi-level analysis showed that the full models accounted for about $82 \%$ and $39 \%$ of the odds of thinness or overweight/obese across the communities, respectively. Household size (adjusted OR (aOR) 1.10; $P=0.001 ; 95 \%$ CI (1.04, $1 \cdot 16)$ ) increased the odds, while the upper wealth index (aOR $0.43 ; P=0.016$; $95 \%$ CI $(0.22,0.86))$ decreased the odds of thinness. Age (aOR 0.86; $P<0.001$; $95 \%$ CI $(1.26,8.70)$ ), exclusive breastfeeding (aOR 0.46; $P=0.010 ; 95 \% \mathrm{CI}$ $(0.25,0.83))$, physical activity (aOR 0.55; $P=0.001 ; 95 \% \mathrm{CI}(0.39,0.78))$ and the upper wealth index (aOR 0.47; $P=0.018 ; 95 \%$ CI $(0.25,0.88)$ ) were inversely related with overweight/obesity, while residing in Osun State (aOR 3.32; $P=0.015 ; 95 \%$ CI $(1.26,1.70)$ ), female gender (aOR $1.73 ; P=0.015 ; 95 \%$ CI $(1.11,2.69))$ and screen time $>2 \mathrm{~h} / \mathrm{d}($ aOR $2.33 ; P=0.005 ; 95 \%$ CI $(1.29,4 \cdot 19))$ were positively associated with overweight/obesity.

Conclusions: The study shows that selected community and individual-level factors are strongly associated with thinness and overweight/obesity among school-aged children and adolescents.
\end{abstract}



Obesity is a global challenge, and the prevalence of overweight and obesity is increasing at a faster rate in low- and middle-income countries as compared with high-income countries ${ }^{(1)}$. At the same time, the challenge of under-nutrition persists still in many low- and middleincome countries ${ }^{(2)}$. Thus, many low and middle-income countries are confronted with a double burden of malnutrition $^{(3)}$, with co-existing high level of under-nutrition and an increasing level of over-nutrition ${ }^{(4)}$. Several factors are associated with malnutrition, and the ecological systems model has been proposed to understand child

Last updated 06 May 2022 nutrition processes ${ }^{(5)}$. Ecological systems are the contextual factors within which individuals are nested ${ }^{(6,7)}$.

While the ecological systems theory recognises the impact of the child's individual factors in affecting development, it conceptualises that these factors are just one group out of many others ${ }^{(6,8)}$. In the original work on the ecological systems theory, four different inter-related environments are identified, with the microsystem as the most proximal level, followed by the mesosystem, the exosystem and the macrosystem level. While the most proximal level reflects individual and intrafamilial processes, the outermost system reflects the cultural, religious and socio-economic organisation of the 
community ${ }^{(6,8)}$. The chronosystem is the fifth and final level of Bronfenbrenner's ecological systems theory; it encompasses the concept of time and consists of the environmental changes and transitions that occur over the lifetime and influence the child's development. The theory was later updated to emphasise the important role the individual plays in the development process ${ }^{(7)}$. It was hypothesised that human development was the result of the interplay among four processes: person, context, process and time, with 'person' factors to mean individual characteristics, the 'context' to refer to the external factors described in the original work on the ecological systems theory, the 'process' to refer to the interaction between the person and the context and this development to be understood with reference to 'time ${ }^{,(7,8)}$.

Most of the research efforts targeted at identifying the determinants of the nutritional status of school-aged children and adolescents have focussed mainly at the individual factors alone. A number of studies have reported a significant relationship between nutritional status and such factors as age and gender of the child ${ }^{(9,10)}$, residence ${ }^{(11,12)}$, physical activity ${ }^{(13,14)}$ and feeding patterns ${ }^{(11,15)}$ of children. However, there is little evidence on the relationship between the nutritional status of school-aged children and adolescents and the communities within which the children live. Little or no evidence exists in Nigeria about the relationship between the nutritional status of this group of children and community-level factors, and very few studies have explored ecological factors as determinants of child nutrition beyond the individual factors.

There is a need to focus on the determinants of the nutritional status of school-aged children and adolescents in Nigeria, because identifying the determinants has not been the focus of most research efforts on the subject in Nigeria $^{(16-18)}$. The interest of majority of the researchers in this field in Nigeria has been the assessment and description of the nutritional status. Identifying the determinants is important, not only in improving the understanding about the subject, but especially in planning appropriate nutritional interventions for the children.

Identifying the individual and contextual determinants, using multi-level modelling however, has added advantages. Firstly, conventional regression models assume the units of analysis are not dependent, and this is not usually true. This error may then lead to over-estimation of statistical significance ${ }^{(19)}$. Designing interventions based on erroneous evidence may lead to ineffectiveness of such interventions. Additionally, identifying the contextual determinants will help to understand the dynamics of the influence of the contextual units ${ }^{(19)}$, and especially the potentials they hold for reducing the burden of a complex health challenge such as the double burden of under- and over-nutrition.

While multi-level modelling has been used to explain the determinants of the nutritional status of children under the age of 5 years in Nigeria ${ }^{(20,21)}$, to date, data are lacking for school-aged children and adolescents in Nigeria. This study, therefore, aimed to identify individual and contextual factors that are associated with either underor over-nutrition among both school-aged children and adolescents in two Nigerian states.

\section{Materials and methods}

\section{Study design and setting}

This community-based cross-sectional study was carried out in two Nigerian states. School-aged children and adolescents aged between 6 and 19 years and their mothers formed the study population. The sample size was calculated to get an absolute precision of $\pm 5 \%$ for prevalence estimates using STATCALC on the Epi-Info software ${ }^{(22)}$, and a design effect of 1.5 , which is an adjustment for the sampling technique (multi-stage) used. After correcting for an anticipated non-response rate of $10 \%$, the sample size came to 561 and was rounded off to 600 for each state, making a total of 1200 .

The classification of Nigeria's six geo-political zones in Nigeria according to their wealth index by the Nigeria demographic and health survey ${ }^{(23)}$ was used in selecting the states for this study. One state each from the zones with the lowest (North-east zone) and the highest wealth index (South-west zone) were selected using simple random sampling technique (balloting method). Selection of states was done according to wealth index and geo-political zones because these were the two most consistent factors that were significantly associated with malnutrition from previous similar studies in Nigeria ${ }^{(20,21,24)}$. Gombe and Osun States were selected from the North-east and the South-west zones, respectively. The 1200 children 6-19 years old and their mothers who constituted the study population were then selected using the multi-stage sampling technique.

\section{Data collection}

Data collection was carried out with intervieweradministered pre-tested structured questionnaires using REDCap $^{(25)}$, a data collection software installed on electronic tablets. The mothers were the respondents for the sections on general characteristics of the child, household/family characteristics and community factors. The school-aged children or adolescents responded to the sections on the dietary diversity, physical activity patterns and pubertal staging. Anthropometric measurements of the children and mothers were taken according to standard protocols recommended by the International Society for the Advancement of Kinanthropometry ${ }^{(26)}$. Weight was measured in $0 \cdot 1 \mathrm{~kg}$ by use of Omron ${ }^{\circledR}$ electronic bathroom weighing scale. Height was measured to the nearest $0 \cdot 1$ metre using a stadiometer. Weighing scales were routinely standardised by the use of known weights.

Screen time was the time in hours that the child spent with television, computer, video games or phones/d. The 
physical activity was assessed using the physical activity questionnaire for older children and adolescents by Kowalski et al. ${ }^{(27)}$ from which a composite score of 1 to 5 was derived (higher scores represent higher physical activity levels).

\section{Statistical analyses}

\section{Measures}

The primary outcome/dependent variable was the nutritional status, which was assessed using the BMI-for-age according to WHO reference values ${ }^{(28)}$. It was categorised into: (1) thinness; (2) normal and (3) overweight/obese. The independent variables used were those that had been previously reported from similar studies ${ }^{(20,21)}$ and are presented in Table 1 . The independent variables consist of three groups of variables: individual, household and community-level factors, but the individual and householdlevel factors were collapsed into the individual-level factors for the multi-level analysis. Communities were taken as those who shared a common enumeration area, which served as the primary sampling unit. Household wealth index was calculated using ownership of some household possessions, as it was used by the Nigeria demographic and health survey ${ }^{(23)}$. Principal component analysis was then used to produce a common factor score (household wealth index score) for each household. These scores were used to categorise wealth index into three: (1) poor; (2) middle and (3) rich. The community wealth index was calculated by finding the median wealth index score for each community, and these were then categorised into: (1) low and (2) high using the median value. Pubertal staging was assessed using the Tanner pubertal self-rating scale ${ }^{(29)}$.

\section{Data analysis}

The data were analysed by use of STATA version $15.1^{(30)}$. At the bivariate level, cross-tabulations were done using Pearson's chi-squared test for the categorical variables. The Mann-Whitney $U$ and Kruskal-Wallis tests (nonparametric) were used to test for association among the continuous variables with two and more than two independent variables, respectively. These tests were used because the continuous variables were not normally distributed.

Two-level multi-level binary logistic regression analysis was done to investigate the extent to which the individual and community-level factors explained the variation in under- and over-nutrition in the two Nigerian states. This involved 1200 school-aged children and adolescents (level 1) nested within forty communities (level 2). Enumeration areas, as demarcated by the National Population Commission for 2006 population census in Nigeria $^{(31)}$, were used as communities in this study, and a total of forty enumeration areas were selected (twenty in each of the two states). Two separate multilevel analyses identified the individual and contextual factors associated with either under- or over-nutrition.
Hence, the nutritional status of the school-aged children and adolescents, which was initially categorised into: (1) thinness; (2) normal and (3) overweight/obese, was recoded to form two different dependent variables which were thinness (categorised as (1) thinness (0) otherwise) and overweight/obesity (categorised as (1) overweight/obese (0) otherwise). Firstly, thinness was retained as 'thinness', while normal and overweight/ obesity were merged as 'otherwise' (1 - Thinness, 0 otherwise). For the second dependent variable, overweight/obesity were retained as such, while normal and thinness were merged as 'otherwise' (1 - overweight/obesity, 0 - otherwise). Six models each (total of twelve models) were fitted in all. The first model (Model 0) was the empty model, and the second model (Model 1) considered only the states (Osun and Gombe States), while the third model (Model 2) incorporated the child characteristics to Model 1. The fourth model (Model 3) incorporated the household/family characteristics into the first model. The community-level factors alone were considered in the fifth model (Model 4), while the sixth model (Model 5) is the full model that incorporated all factors into the multi-level analysis. Ethnicity was not included because of a high variance inflation factor when multi-collinearity diagnostics were done.

The fixed effects were used as the measures of association and expressed as adjusted OR (aOR) with the $95 \% \mathrm{CI}$ and the $P$ values. The random effects, which measured variations, were intra-class correlation or the variance partition coefficient and the proportional change in variance. Akaike information criteria were used to determine the goodnessof-fit of the models, where a lower value indicated a better $\mathrm{fit}^{(32)}$. The independent structure, which is the default for the STATA software, was used in the present study.

\section{Results}

The prevalence rates of thinness and overweight/obesity were $10.3 \%$ and $11.4 \%$, respectively, while $21.7 \%$ had one form of malnutrition or the other (Fig. 1). Gombe State has a higher prevalence of thinness (13.8\% v. 6.7\%) and lower prevalence of overweight/obesity $(6.8 \% v$. $16.0 \%$ ). The prevalence rate of malnutrition (under- and over-nutrition) was $22.7 \%$ for Osun State and $20.6 \%$ for Gombe State.

The description of all individual- and community-level factors according to the states is shown in Supplemental Table 1. Table 2 shows that all the child characteristics had a statistically significant association with the nutritional status of the respondents $(P<0.05)$ at the bivariate analysis level, except education $(P=0.86)$, birth order $(P=0.06)$ and pubertal staging $(P=0.06)$. All the household/family factors had a statistically significant association with the nutritional status of the older children $(P<0.05)$, except marital status $(P=0.61)$ and family type $(P=0.67)$. All 
Table 1 Definitions for independent variables

\begin{tabular}{|c|c|}
\hline Independent variables & Description \\
\hline \multicolumn{2}{|l|}{ Individual-level factors } \\
\hline Age of child (years) & Expressed as a continuous variable \\
\hline Sex of child & Categorised into (1) male (2) female \\
\hline Birth order & Categorised into (1) 1 (2) $2-4(3)>4$ \\
\hline Education & Categorised into (1) currently in school (2) previously in school (3) never in school \\
\hline Birth weight & Categorised into (1) low $<2.5 \mathrm{~kg}(2)$ normal $2.5-4 \mathrm{~kg}(3)>4 \mathrm{~kg}$ \\
\hline Breastfeeding duration & Expressed as a continuous variable (months) \\
\hline Immunisation status & Categorised into (1) complete (2) incomplete \\
\hline Birth place & Categorised into (1) others (2) hospital \\
\hline Exclusively breastfed for 6 months & Categorised into (1) yes (2) no \\
\hline Child's health & $\begin{array}{l}\text { This is the mother's perception of the child's health and it was categorised into (1) very good, (2) } \\
\text { good and (3) not too good }\end{array}$ \\
\hline Puberty stage & Categorised into stages $1-5$ (Tanner staging) \\
\hline Screen time (in hours) & Categorised as $(1)<2 \mathrm{~h}(2) \geq 2 \mathrm{~h}$ \\
\hline Physical activity & Expressed as continuous variable (scores) \\
\hline \multicolumn{2}{|l|}{ Household/family factors } \\
\hline Household size & Expressed as continuous variable \\
\hline Number of children & Expressed as continuous variable \\
\hline Wealth index & Categorised into (1) Poor, (2) Middle and (3) Rich \\
\hline Marital status & Categorised into (1) single, (2) married and (3) previously married \\
\hline Family type & Categorised into (1) monogamous and (2) polygamous \\
\hline Maternal education & Categorised into (1) less than secondary and (2) secondary or more \\
\hline Father's education & Categorised into (1) less than secondary and (2) secondary or more \\
\hline Mother's unemployment & Categorised into (1) employed and (2) unemployed \\
\hline \multicolumn{2}{|l|}{ Community-level factors } \\
\hline State & Categorised into (1) Gombe and (2) Osun \\
\hline Residence & Categorised into (1) rural and (2) urban \\
\hline Community wealth index & $\begin{array}{l}\text { Categorised into (1) low (2) high, using the median of the community wealth index scores as } \\
\text { reference }\end{array}$ \\
\hline Maternal education & Categorised into (1) low (2) high, using the median as reference \\
\hline Safe water & Categorised into (1) low (2) high, using the median as reference \\
\hline
\end{tabular}

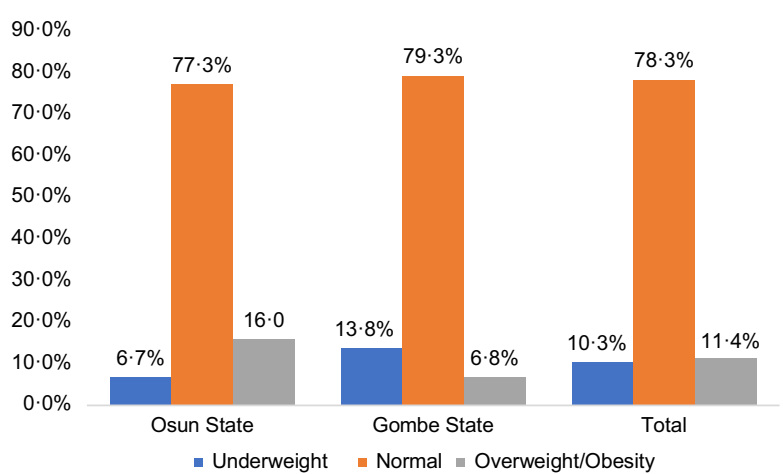

Fig. 1 Distribution of the nutritional status among school-aged children and adolescents by state

the community-level factors had a statistically significant association with the nutritional status of the children $(P<0 \cdot 001)$.

Table 3 shows the results of the multi-level analyses for thinness (under-nutrition), highlighting the fixed and random effects. The full model shows that household size (aOR 1.10; $P=0.001 ; 95 \% \mathrm{CI}(1.04,1.16))$ and the uppermost wealth index (rich) (aOR 0.43; $P=0.016 ; 95 \% \mathrm{CI}$ $(0.22,0.86))$ had a significant positive and inverse associations with thinness, respectively. Concerning the measures of variations for thinness, as shown with the random effects on Table 3, the intra-class correlation for the intercept-only model (i.e. no explanatory variable) was $21.6 \%$. This implies that $21.6 \%$ of the variation in the odds of thinness was attributable to community-level variables, and this was statistically significant $(P<0 \cdot 001)$. The Models $1,2,3,4$ and 5 account for about $22 \cdot 1 \%, 51.8 \%, 41.2 \%, 56.7 \%$ and $80.2 \%$ in the odds of under-nutrition across the communities, as explained by the proportional change in variance. The model with the best fit is Model 3, which controlled for State and the Household/family characteristics, with Akaike information criteria of 740.41 compared with $753 \cdot 3$ for the empty model (Model 0).

Table 4 shows the results of the multi-level analysis for overweight/obesity (over-nutrition). Age (aOR 0.86; $P<0.001 ; 95 \%$ CI $(1.26,8.70))$, exclusive breastfeeding (aOR $0.46 ; P=0.010 ; 95 \% \mathrm{CI}(0.25,0.83))$, physical activity (aOR $0.55 ; P=0.001 ; 95 \% \mathrm{CI}(0.39,0.78)$ ) and the rich wealth index (aOR 0.47; $P=0.018 ; 95 \%$ CI $(0 \cdot 25,0 \cdot 88)$ ) had an inverse relationship with overweight/obesity, while residing in Osun State (aOR 3.32; $P=0.015 ; 95 \%$ CI (1.26, $1 \cdot 70)$ ), female gender (aOR $1.73 ; P=0.015 ; 95 \%$ CI ( 1.11 , $2.69)$ ) and screening time $>2 \mathrm{~h} / \mathrm{d}($ aOR $2.33 ; P=0.005$; $95 \%$ CI $(1 \cdot 29,4 \cdot 19))$ were positively associated with overweight/obesity. The empty model (Model 0) shows a statistically significant variation in the odds of childhood overweight/obesity across the communities $(P<0.001)$. As indicated by the intra-class correlation, $28.5 \%$ of the variance in the odds of overweight/obesity among the children could be ascribed to community-level factors. The 
Table 2 Association between the individual- and community-level factors and nutritional status at bivariate analysis level

\begin{tabular}{|c|c|c|c|c|c|c|c|}
\hline \multirow[b]{2}{*}{ Variables } & \multicolumn{6}{|c|}{ Nutritional status (\%) } & \multirow[b]{2}{*}{ Statistics } \\
\hline & \multicolumn{2}{|c|}{ Thinness } & \multicolumn{2}{|c|}{ Normal } & \multicolumn{2}{|c|}{$\begin{array}{l}\text { Overweight/ } \\
\text { obesity }\end{array}$} & \\
\hline \multicolumn{8}{|l|}{ Individual-level factors - child characteristics } \\
\hline Age of the child (IR) & $12 \cdot 0$ & $7 \cdot 0$ & $12 \cdot 0$ & $6 \cdot 0$ & $10 \cdot 0$ & $4 \cdot 0$ & $\dagger P<0.001^{*}$ \\
\hline Breastfeeding duration (months) (IR) & $18 \cdot 0$ & $8 \cdot 0$ & $18 \cdot 0$ & $9 \cdot 0$ & $18 \cdot 0$ & $8 \cdot 0$ & $\dagger P=0.046^{\star}$ \\
\hline \multicolumn{8}{|l|}{ Sex } \\
\hline Male & 67 & 11.1 & 481 & $80 \cdot 0$ & 53 & 8.8 & $P=0.014^{\star}$ \\
\hline Female & 56 & $9 \cdot 3$ & 459 & $76 \cdot 6$ & 84 & $14 \cdot 0$ & \\
\hline \multicolumn{8}{|l|}{ Child education } \\
\hline Currently in-school & 116 & 10.5 & 866 & $78 \cdot 3$ & 124 & $11 \cdot 2$ & $P=0.855$ \\
\hline Previously in-school & 4 & $7 \cdot 0$ & 45 & 78.9 & 8 & $14 \cdot 0$ & \\
\hline Never attended school & 3 & $8 \cdot 1$ & 29 & $78 \cdot 4$ & 5 & 13.5 & \\
\hline \multicolumn{8}{|l|}{ Birth weight of the child } \\
\hline Small $(<2.5 \mathrm{~kg})$ & 17 & $10 \cdot 2$ & 135 & $80 \cdot 8$ & 15 & $9 \cdot 0$ & $P=0.003^{*}$ \\
\hline Normal $(2 \cdot 5-4$ kg) & 91 & $10 \cdot 9$ & 629 & $75 \cdot 6$ & 112 & 13.5 & \\
\hline $\operatorname{Big}(>4 \mathrm{~kg})$ & 15 & 7.5 & 176 & 87.6 & 10 & $5 \cdot 0$ & \\
\hline \multicolumn{8}{|l|}{ Birth place of the child } \\
\hline Others & 32 & $14 \cdot 6$ & 167 & $76 \cdot 3$ & 20 & $9 \cdot 1$ & $P=0.042^{\star}$ \\
\hline Hospital & 91 & $9 \cdot 3$ & 773 & $78 \cdot 8$ & 117 & 11.9 & \\
\hline \multicolumn{8}{|l|}{ Exclusively breastfed } \\
\hline No & 65 & 13.1 & 385 & $77 \cdot 6$ & 46 & $9 \cdot 3$ & $P=0.006^{\star}$ \\
\hline Yes & 58 & $8 \cdot 2$ & 555 & $78 \cdot 8$ & 91 & $12 \cdot 9$ & \\
\hline Immunisation status of child & & & & & & & \\
\hline Not immunised & 6 & 28.6 & 13 & 61.9 & 2 & 9.5 & $P=0.012^{\star}$ \\
\hline Partially immunised & 26 & $16 \cdot 5$ & 116 & 73.4 & 16 & $10 \cdot 1$ & \\
\hline Fully immunised & 86 & 8.8 & 773 & 79.5 & 113 & 11.6 & \\
\hline Not sure & 5 & $10 \cdot 2$ & 38 & 77.6 & 6 & $12 \cdot 2$ & \\
\hline Birth order of the child & & & & & & & \\
\hline 1 & 58 & 9.7 & 460 & $77 \cdot 2$ & 78 & $13 \cdot 1$ & $P=0.063$ \\
\hline $2-4$ & 53 & $11 \cdot 2$ & 366 & 77.5 & 53 & $11 \cdot 2$ & \\
\hline$>4$ & 12 & $9 \cdot 1$ & 114 & 86.4 & 6 & 4.5 & \\
\hline Screen time (hours) (IR) & $2 \cdot 0$ & $3 \cdot 0$ & $2 \cdot 8$ & 3.2 & 3.0 & $3 \cdot 0$ & $\dagger P<0.001^{\star}$ \\
\hline Physical activity scores (IR) & $2 \cdot 0$ & $1 \cdot 1$ & $2 \cdot 3$ & 1.0 & $2 \cdot 1$ & 0.8 & $\dagger P<0.001^{*}$ \\
\hline Child's health & & & & & & & \\
\hline Very good & 39 & $7 \cdot 8$ & 391 & 78.4 & 69 & $13 \cdot 8$ & $P<0.001^{*}$ \\
\hline Good & 57 & $9 \cdot 7$ & 473 & $80 \cdot 6$ & 57 & $9 \cdot 7$ & \\
\hline Not too good & 27 & 23.7 & 76 & $66 \cdot 7$ & 11 & $9 \cdot 6$ & \\
\hline Pubertal staging & & & & & & & \\
\hline Stage 1 & 32 & $9 \cdot 7$ & 268 & $81 \cdot 2$ & 30 & $9 \cdot 1$ & $P=0.061$ \\
\hline Stage 2 & 37 & $9 \cdot 2$ & 328 & $81 \cdot 2$ & 39 & $9 \cdot 7$ & \\
\hline Stage 3 & 35 & $10 \cdot 7$ & 238 & $72 \cdot 8$ & 54 & $16 \cdot 5$ & \\
\hline Stage 4 & 16 & 13.8 & 89 & $76 \cdot 7$ & 11 & 9.5 & \\
\hline Stage 5 & 3 & 13.0 & 17 & 73.9 & 3 & $13 \cdot 0$ & \\
\hline Individual-level factors -household/famil & racteristi & & & & & & \\
\hline Household size (IR) & $7 \cdot 0$ & $5 \cdot 0$ & $6 \cdot 0$ & $3 \cdot 0$ & $5 \cdot 0$ & $2 \cdot 0$ & $\dagger P<0.001^{*}$ \\
\hline Children in the household (IR) & $5 \cdot 0$ & $3 \cdot 0$ & $4 \cdot 0$ & $2 \cdot 0$ & $3 \cdot 0$ & 1.0 & $\dagger P<0.001^{\star}$ \\
\hline Household wealth index & & & & & & & \\
\hline Poor & 61 & $15 \cdot 3$ & 294 & 73.5 & 45 & $11 \cdot 3$ & $P<0.001^{*}$ \\
\hline Middle & 44 & $11 \cdot 0$ & 312 & $78 \cdot 0$ & 44 & $11 \cdot 0$ & \\
\hline Rich & 18 & 4.5 & 334 & 83.5 & 48 & $12 \cdot 0$ & \\
\hline Marital status & & & & & & & \\
\hline Single & 1 & 12.5 & 5 & $62 \cdot 5$ & 2 & $25 \cdot 0$ & $P=0.606$ \\
\hline Married & 117 & $10 \cdot 4$ & 879 & $78 \cdot 1$ & 129 & 11.5 & \\
\hline Previously married & 5 & 7.5 & 56 & 83.6 & 6 & $9 \cdot 0$ & \\
\hline Family type & & & & & & & \\
\hline Monogamous & 107 & $10 \cdot 1$ & 833 & $78 \cdot 3$ & 124 & 11.7 & $P=0.667$ \\
\hline Polygamous & 16 & 11.8 & 107 & $78 \cdot 7$ & 13 & $9 \cdot 6$ & \\
\hline Mother's education & & & & & & & \\
\hline Less than secondary & 61 & $16 \cdot 3$ & 283 & $75 \cdot 7$ & 30 & 8.0 & $P<0.001^{*}$ \\
\hline Secondary or more & 62 & 7.5 & 657 & 79.5 & 107 & $13 \cdot 0$ & \\
\hline Father's education & & & & & & & \\
\hline Less than Secondary & 35 & $15 \cdot 2$ & 170 & $73 \cdot 6$ & 26 & $11 \cdot 3$ & $P=0.023^{\star}$ \\
\hline Secondary or more & 88 & $9 \cdot 1$ & 770 & 79.5 & 111 & 11.5 & \\
\hline Mother's employment & & & & & & & \\
\hline Employed & 77 & $8 \cdot 1$ & 759 & $79 \cdot 5$ & 119 & $12 \cdot 5$ & $P<0.001^{\star}$ \\
\hline Unemployed & 46 & $18 \cdot 8$ & 181 & 73.9 & 18 & $7 \cdot 3$ & \\
\hline Community-level factors & & & & & & & \\
\hline
\end{tabular}




\begin{tabular}{|c|c|c|c|c|c|c|c|}
\hline \multirow[b]{2}{*}{ Variables } & \multicolumn{6}{|c|}{ Nutritional status (\%) } & \multirow[b]{2}{*}{ Statistics } \\
\hline & \multicolumn{2}{|c|}{ Thinness } & \multicolumn{2}{|c|}{ Normal } & \multicolumn{2}{|c|}{$\begin{array}{l}\text { Overweight/ } \\
\text { obesity }\end{array}$} & \\
\hline \multicolumn{7}{|l|}{ State } & \\
\hline Gombe & 83 & $13 \cdot 8$ & 476 & $79 \cdot 3$ & 41 & $6 \cdot 8$ & $P<0.001^{*}$ \\
\hline Osun & 40 & $6 \cdot 7$ & 464 & $77 \cdot 3$ & 96 & $16 \cdot 0$ & \\
\hline \multicolumn{8}{|l|}{ Residence } \\
\hline Rural & 77 & $12 \cdot 8$ & 481 & $80 \cdot 2$ & 42 & $7 \cdot 0$ & $P<0.001^{*}$ \\
\hline Urban & 46 & $7 \cdot 7$ & 459 & 76.5 & 95 & $15 \cdot 8$ & \\
\hline \multicolumn{8}{|c|}{ Community wealth index } \\
\hline Low & 79 & $13 \cdot 2$ & 477 & 79.5 & 44 & $7 \cdot 3$ & $P<0.001^{*}$ \\
\hline High & 44 & $7 \cdot 3$ & 463 & $77 \cdot 2$ & 93 & $15 \cdot 5$ & \\
\hline \multicolumn{8}{|c|}{ Mother's education } \\
\hline Low & 85 & $14 \cdot 2$ & 472 & $78 \cdot 7$ & 43 & $7 \cdot 2$ & $P<0.001^{*}$ \\
\hline High & 38 & $6 \cdot 3$ & 468 & $78 \cdot 0$ & 94 & $15 \cdot 7$ & \\
\hline \multicolumn{8}{|l|}{ Safe water } \\
\hline Low & 69 & 14.4 & 370 & $77 \cdot 1$ & 370 & $77 \cdot 1$ & $P<0.001^{*}$ \\
\hline High & 54 & 7.5 & 570 & 79.2 & 96 & $13 \cdot 3$ & \\
\hline
\end{tabular}

$\mathrm{IR}$, interquartile range; Screen time, time spent watching television, with phone, computer or computer. ${ }^{*}$ Statistically significant.

†Kruskal-Wallis test (non-parametric) was used because the variables were not normally distributed.

Models 1, 2, 3, 4 and 5 account for about 23.4\%, 35.3\%, $18.2 \%, 48.1 \%$ and $39.2 \%$ in the odds of over-nutrition across the communities, as explained by the proportional change in variance. The statistically significant variation across communities persisted even after controlling for all the variables $(P<0 \cdot 001)$. Model 2 , which controlled for the state and child characteristics, had the best fit with Akaike information criteria of $752 \cdot 76$. (Table 4).

\section{Discussion}

This study, to the best our knowledge, is the first attempt to simultaneously consider the influence of individualand community-level factors as predictors of under- and over-nutrition among school-aged and adolescents in Nigeria. Most previous studies have focussed on various indicators of under-nutrition among categories of underfive children. It is also the first study that used multi-level analysis to identify the predictors of overweight/obesity among any group of children or adolescents in Nigeria. Furthermore, the present study controlled for a wide range of independent variables, making it one of the most comprehensive studies on the determinants of nutritional status of any category of children and/or adolescents in Nigeria.

The ecological systems theory has underscored the importance of not only the compositional factors (i.e. the individual-level factors), but also the contextual factors (i.e. community-level factors) in trying to understand a complex and highly important process like child nutrition $^{(6,7)}$. The multi-level analysis that was done in this study therefore helped to account for the variations in under- and over-nutrition of older children across the different contextual units, as well as to identify the compositional and contextual factors that were associated with under- and over-nutrition among the older children in the two Nigerian States.

A major finding of this study is the importance of community variation and community-level factors in the prevalence of thinness and overweight/obesity among children 6-19 years old in the two Nigerian states. As indicated by the intra-class correlation of the intercept-only model (i.e. no explanatory variable incorporated), about $22 \%$ and $29 \%$ of the variance in the odds for thinness and overweight/obesity among the children could be ascribed to community-level factors, respectively. Apart from the full model that included all explanatory variables, the model which consisted of community-level factors only (these factors include the state, residence, wealth index, maternal education and safe water), accounted for the highest variation observed for children that were thin (57\%) and overweight/obese (48\%). This suggests that school-aged children and adolescents from the same communities are influenced by common factors, and hence the potential for community-level interventions.

The present study found the odds for thinness increased by $10 \%$ for every unit increase in household size. Not many studies among children have explored the relationship between under-nutrition and household size, but some studies have however looked at other variables that could serve as proxy for the household size. For example, Nnebue et $a l .{ }^{(33)}$ found a statistically significant relationship between under-nutrition and the number of siblings a child has. This finding further underscores the need for increased efforts in promoting family planning in Nigeria, because a larger number of children may put a household at higher risk of poverty and hence of under-nutrition. The household wealth index was also significantly associated with 


\section{Public Health Nutrition}

Table 3 Individual and contextual factors associated with thinness among school-aged children and adolescents in two Nigerian states using a two-level multi-level analysis

\begin{tabular}{|c|c|c|c|c|c|c|c|c|c|c|c|}
\hline \multirow[b]{2}{*}{ Variables } & Model 0 & \multicolumn{2}{|c|}{ Model 1} & \multicolumn{2}{|c|}{ Model 2} & \multicolumn{2}{|c|}{ Model 3} & \multicolumn{2}{|c|}{ Model 4} & \multicolumn{2}{|c|}{ Model 5} \\
\hline & $95 \% \mathrm{Cl}$ & OR & $95 \% \mathrm{Cl}$ & OR & $95 \% \mathrm{Cl}$ & OR & $95 \% \mathrm{Cl}$ & OR & $95 \% \mathrm{Cl}$ & OR & $95 \% \mathrm{Cl}$ \\
\hline \multicolumn{12}{|l|}{$\begin{array}{l}\text { States } \\
\text { Gombe }{ }^{\circledR}\end{array}$} \\
\hline Osun & & ${ }^{*} 0.499$ & $0.25,0.99$ & 0.521 & $0.25,1.09$ & 0.576 & $0.29,1.14$ & 0.620 & $0.33,1.16$ & 0.696 & $0.33,1.48$ \\
\hline \multicolumn{12}{|l|}{ Individual-level factors - child characteristics } \\
\hline Age & & & & 0.977 & $0.92,1.04$ & & & & & 0.976 & $0.91,1.04$ \\
\hline Breastfeeding (months) & & & & 1.031 & $0.99,1.08$ & & & & & 1.029 & $0.98,1.08$ \\
\hline \multicolumn{12}{|l|}{$\begin{array}{l}\text { Gender } \\
\text { Male }{ }^{\circledR}\end{array}$} \\
\hline Female & & & & 0.933 & $0.61,1.43$ & & & & & 0.914 & $0.59,1.42$ \\
\hline \multicolumn{12}{|l|}{ Birth weight } \\
\hline \multicolumn{12}{|l|}{ Small $(<2.5 \mathrm{~kg}){ }^{\circledR}$} \\
\hline Normal $(2 \cdot 5-4 \mathrm{~kg})$ & & & & 1.248 & $0.67,2.31$ & & & & & 1.081 & $0.58,2.02$ \\
\hline $\operatorname{Big}(>4 \mathrm{~kg})$ & & & & 0.836 & $0.37,1.91$ & & & & & 0.603 & $0.26,1.42$ \\
\hline \multirow{2}{*}{\multicolumn{12}{|c|}{$\begin{array}{l}\text { Hospital birth } \\
\text { No }{ }^{\circledR}\end{array}$}} \\
\hline & & & & & & & & & & & \\
\hline Yes & & & & 0.950 & $0.55,1.65$ & & & & & 1.284 & $0.71,2 \cdot 31$ \\
\hline \multirow{2}{*}{\multicolumn{12}{|c|}{$\begin{array}{l}\text { Child education } \\
\text { Currently in-school }{ }^{\circledR}\end{array}$}} \\
\hline & & & & & & & & & & & \\
\hline Previously in school & & & & 0.649 & $0.21,1.97$ & & & & & 0.613 & $0.19,1.97$ \\
\hline Never in school & & & & 0.341 & $0.09,1.29$ & & & & & 0.379 & $0.10,1.43$ \\
\hline \multicolumn{12}{|l|}{ Immunisation } \\
\hline \multicolumn{12}{|l|}{ Not immunised ${ }^{\circledR}$} \\
\hline Partially immunised & & & & 0.786 & $0.23,2.71$ & & & & & 1.063 & $0.26,4.28$ \\
\hline Fully immunised & & & & 0.566 & $0.16,1.97$ & & & & & 0.958 & $0.23,3.99$ \\
\hline Not sure & & & & 0.559 & $0.12,2.58$ & & & & & 0.508 & $0.09,2.78$ \\
\hline \multicolumn{12}{|l|}{$\begin{array}{l}\text { Birth order } \\
1 \circledast\end{array}$} \\
\hline $2-4$ & & & & 1.017 & $0.65,1.59$ & & & & & 1.022 & $0.64,1.63$ \\
\hline$>4$ & & & & 0.737 & $0.36,1.53$ & & & & & 0.537 & $0.22,1.32$ \\
\hline \multicolumn{12}{|l|}{$\begin{array}{l}\text { Exclusive breastfeeding } \\
\text { No }{ }^{\circledR}\end{array}$} \\
\hline Yes & & & & 0.828 & $0.49,1.39$ & & & & & 0.895 & $0.52,1.54$ \\
\hline \multicolumn{12}{|l|}{$\begin{array}{l}\text { Screen time } \\
<2 \mathrm{~h} \AA\end{array}$} \\
\hline$\geq 2 \mathrm{~h}$ & & & & 0.677 & $0.43,1.08$ & & & & & 0.805 & $0.49,1.32$ \\
\hline Physical activity scores & & & & 1.072 & $0.80,1.45$ & & & & & 0.963 & $0.71,1.30$ \\
\hline \multicolumn{12}{|l|}{ Child's health } \\
\hline Very good ${ }^{\circledR}$ & & & & & & & & & & & \\
\hline Good & & & & 1.079 & $0.64,1.83$ & & & & & 0.951 & $0.55,1.65$ \\
\hline Not too good & & & & 1.458 & $0.63,3.38$ & & & & & $1 \cdot 127$ & $0.46,2 \cdot 76$ \\
\hline \multicolumn{12}{|l|}{$\begin{array}{l}\text { Puberty stage } \\
1 \AA\end{array}$} \\
\hline 2 & & & & $1 \cdot 193$ & $0.67,2 \cdot 11$ & & & & & 1.282 & $0.71,2 \cdot 30$ \\
\hline 3 & & & & $1 \cdot 179$ & $0.63,2.20$ & & & & & 1.463 & $0.77,2.78$ \\
\hline 4 & & & & 1.937 & $0.87,4.32$ & & & & & 1.506 & $0.65,3.48$ \\
\hline 5 & & & & $2 \cdot 602$ & $0.70,9 \cdot 68$ & & & & & $2 \cdot 350$ & $0 \cdot 60,9 \cdot 19$ \\
\hline
\end{tabular}




\section{Public Health Nutrition}

Table 3 Continued

\begin{tabular}{|c|c|c|c|c|c|c|c|c|c|c|c|c|}
\hline \multirow[b]{2}{*}{ Variables } & \multicolumn{2}{|l|}{ Model 0} & \multicolumn{2}{|c|}{ Model 1} & \multicolumn{2}{|c|}{ Model 2} & \multicolumn{2}{|c|}{ Model 3} & \multicolumn{2}{|c|}{ Model 4} & \multicolumn{2}{|c|}{ Model 5} \\
\hline & OR & $95 \% \mathrm{Cl}$ & OR & $95 \% \mathrm{Cl}$ & OR & $95 \% \mathrm{Cl}$ & OR & $95 \% \mathrm{Cl}$ & OR & $95 \% \mathrm{Cl}$ & OR & $95 \% \mathrm{Cl}$ \\
\hline \multicolumn{13}{|c|}{ Individual-level factors - household/family characteristics } \\
\hline Household size & & & & & & & **1.076 & $1.02,1.13$ & & & $* * * 1.097$ & $1.04,1.16$ \\
\hline Children in the household & & & & & & & 0.936 & $0.85,1.03$ & & & 0.972 & $0.86,1 \cdot 10$ \\
\hline \multicolumn{13}{|l|}{$\begin{array}{l}\text { Wealth index } \\
\text { Poor }{ }^{\circledR}\end{array}$} \\
\hline Middle & & & & & & & 0.827 & $0.51,1.33$ & & & 0.921 & $0.55,1.53$ \\
\hline Rich & & & & & & & ${ }^{* * *} 0.350$ & $0.19,0.66$ & & & ${ }^{*} 0.432$ & $0.22,1.86$ \\
\hline \multicolumn{13}{|l|}{$\begin{array}{l}\text { Marital status } \\
\text { Single }{ }^{\circledR}\end{array}$} \\
\hline Married & & & & & & & 0.596 & $0.06,5.56$ & & & 0.449 & $0.05,4.32$ \\
\hline Previously married & & & & & & & 0.408 & $0.04,4.58$ & & & 0.351 & $0.03,4.25$ \\
\hline \multicolumn{13}{|l|}{$\begin{array}{l}\text { Family type } \\
\text { Monogamous }{ }^{\circledR}\end{array}$} \\
\hline Polygamous & & & & & & & 0.519 & $0.25,1.07$ & & & 0.452 & $0.20,1.02$ \\
\hline \multicolumn{13}{|l|}{$\begin{array}{l}\text { Maternal education } \\
\quad<\text { secondary }{ }^{\circledR}\end{array}$} \\
\hline Secondary or more & & & & & & & 0.775 & $0.45,1.32$ & & & 0.796 & $0.44,1.44$ \\
\hline \multicolumn{13}{|l|}{$\begin{array}{l}\text { Father's education } \\
<\text { Secondary }{ }^{\circledR}\end{array}$} \\
\hline Secondary or more & & & & & & & 1.042 & $0.60,1 \cdot 80$ & & & 1.204 & $0.67,2 \cdot 17$ \\
\hline \multicolumn{13}{|l|}{$\begin{array}{l}\text { Mother's employment } \\
\text { Employed }{ }^{\circledR}\end{array}$} \\
\hline Unemployed & & & & & & & $1 \cdot 111$ & $0.66,1.87$ & & & 1.397 & $0.81,2.41$ \\
\hline \multicolumn{13}{|l|}{$\begin{array}{l}\text { Residence } \\
\text { Rural }{ }^{\circledR}\end{array}$} \\
\hline Urban & & & & & & & & & $1 \cdot 873$ & $0.63,5.55$ & 1.677 & $0.62,4.53$ \\
\hline \multicolumn{13}{|l|}{ Community wealth index } \\
\hline High & & & & & & & & & 0.553 & $0.28,1.07$ & 0.592 & 0.321 .10 \\
\hline \multicolumn{13}{|l|}{ Maternal education } \\
\hline $\begin{array}{l}\text { Low } \\
\text { High }{ }^{\circledR}\end{array}$ & & & & & & & & & ${ }^{*} 0.332$ & $0.12,1.92$ & 0.459 & $0.18,1.19$ \\
\hline \multicolumn{13}{|l|}{$\begin{array}{l}\text { Safe water } \\
\text { Low }{ }^{\circledR}\end{array}$} \\
\hline High & & & & & & & & & 0.637 & $0 \cdot 33,1 \cdot 21$ & 0.733 & $0.41,1.32$ \\
\hline \multicolumn{13}{|l|}{ Random effects } \\
\hline $\begin{array}{l}\text { Community levelVariance (SE) } \\
\text { VPC = ICC (\%) }\end{array}$ & $\begin{array}{l}{ }^{\star * \star} 0.905 \\
21.57 \%\end{array}$ & 0.34 & $\begin{array}{l}\star \star \star * \\
17.705 \%\end{array}$ & 0.29 & $\begin{array}{l}{ }^{* * *} 0.436 \\
11.69 \%\end{array}$ & 0.23 & ${ }^{\star \star *} 0.532$ & 0.25 & ${ }^{* * \star} 0.392$ & 0.21 & $\begin{array}{l}0.179 \\
5.16 \%\end{array}$ & 0.19 \\
\hline $\begin{array}{l}\text { VPC }=I C C(\%) \\
\text { Explained variation (ie PCV in \%) }\end{array}$ & Reference & & $22.10 \%$ & & $51.82 \%$ & & $41.22 \%$ & & $\begin{array}{l}10.64 \% \\
56.69 \%\end{array}$ & & $\begin{array}{r}5.16 \% \\
80.22 \%\end{array}$ & \\
\hline Log likelihood & -374.65 & & -372.85 & & $-356 \cdot 26$ & & $-357 \cdot 20$ & & $-367 \cdot 15$ & & $-337 \cdot 18$ & \\
\hline Model fit statistics (AIC) & $753 \cdot 30$ & & $751 \cdot 70$ & & 762.51 & & 740.41 & & $748 \cdot 31$ & & 752.35 & \\
\hline
\end{tabular}




\section{Public Health Nutrition}

Table 4 Individual and contextual factors associated with over-nutrition among school-aged children and adolescents in two Nigerian states using a two-level multi-level analysis

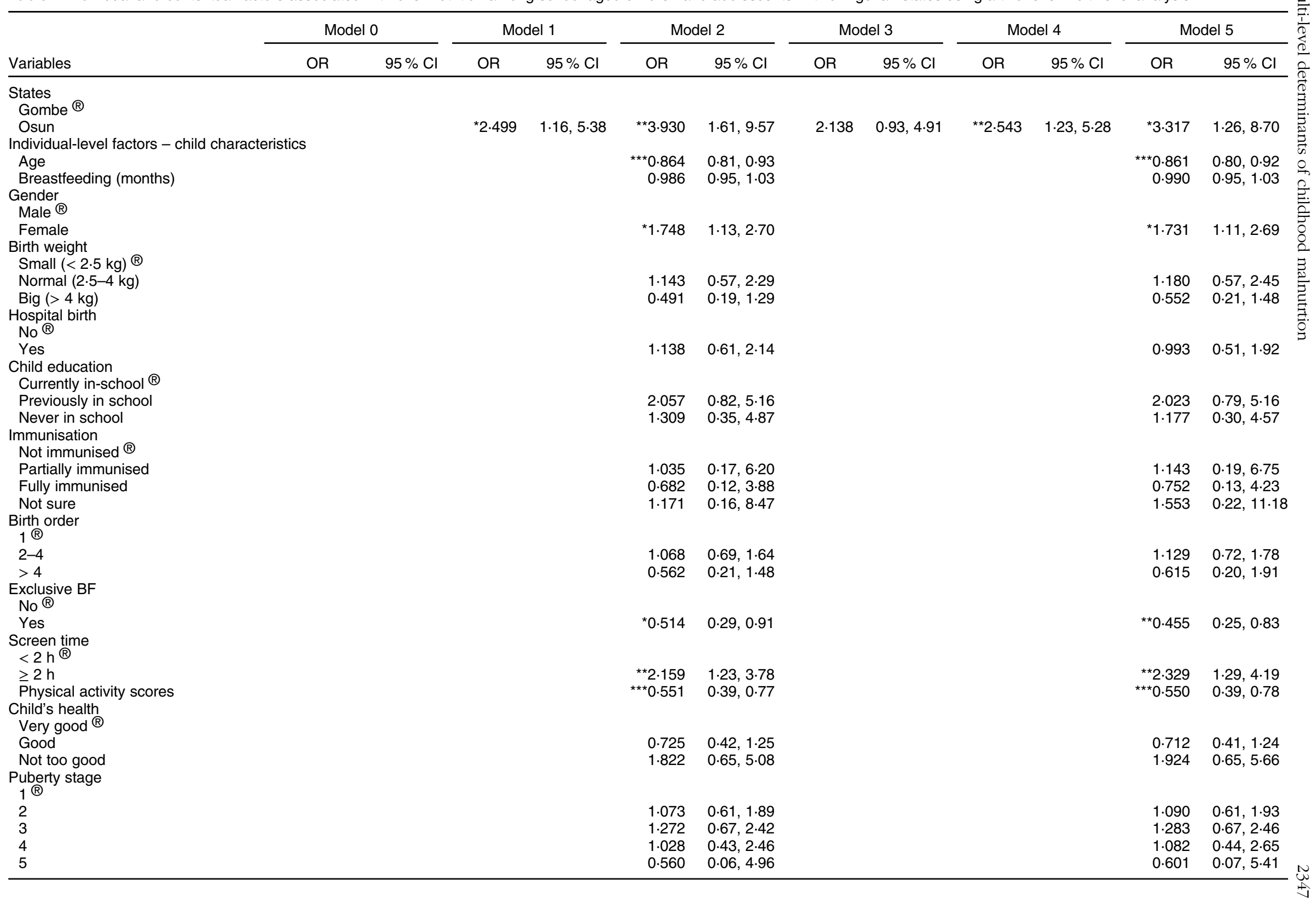




\section{Public Health Nutrition}

Table 4 Continued

\begin{tabular}{|c|c|c|c|c|c|c|c|c|c|c|c|c|}
\hline \multirow[b]{2}{*}{ Variables } & \multicolumn{2}{|l|}{ Model 0} & \multicolumn{2}{|c|}{ Model 1} & \multicolumn{2}{|c|}{ Model 2} & \multicolumn{2}{|c|}{ Model 3} & \multicolumn{2}{|c|}{ Model 4} & \multicolumn{2}{|c|}{ Model 5} \\
\hline & OR & $95 \% \mathrm{Cl}$ & OR & $95 \% \mathrm{Cl}$ & OR & $95 \% \mathrm{Cl}$ & OR & $95 \% \mathrm{Cl}$ & OR & $95 \% \mathrm{Cl}$ & OR & $95 \% \mathrm{Cl}$ \\
\hline \multicolumn{13}{|c|}{ Individual-level factors - household/family characteristics } \\
\hline Household size & & & & & & & 1.003 & $0.93,1.08$ & & & 0.997 & $0.91,1.09$ \\
\hline Children in the household & & & & & & & 0.937 & $0.82,1.07$ & & & 0.991 & $0 \cdot 85,1 \cdot 16$ \\
\hline \multicolumn{13}{|l|}{$\begin{array}{l}\text { Wealth index } \\
\text { Poor }{ }^{\circledR}\end{array}$} \\
\hline Middle & & & & & & & 0.760 & $0.46,6.15$ & & & 0.686 & $0.39,1.20$ \\
\hline Rich & & & & & & & 0.589 & $0.34,5.05$ & & & ${ }^{*} 0.472$ & $0.25,0.88$ \\
\hline \multicolumn{13}{|l|}{ Marital status } \\
\hline Married & & & & & & & 0.933 & $0 \cdot 14,6 \cdot 15$ & & & $1 \cdot 108$ & $0.13,9.63$ \\
\hline Previously married & & & & & & & 0.644 & $0.08,5.05$ & & & 0.677 & $0.07,6.98$ \\
\hline \multicolumn{13}{|l|}{ Family type } \\
\hline Monogamous (R) & & & & & & & & & & & & \\
\hline Polygamous & & & & & & & 1.440 & $0 \cdot 67,3 \cdot 12$ & & & $1 \cdot 646$ & $0.69,3.90$ \\
\hline \multicolumn{13}{|l|}{ Maternal education } \\
\hline Secondary or more & & & & & & & $1 \cdot 730$ & $0.93,3.23$ & & & 2.052 & $0.98,4.32$ \\
\hline \multicolumn{13}{|l|}{ Father's education } \\
\hline Less than Secondary $(\mathrm{R})$ & & & & & & & & & & & & \\
\hline Secondary or more & & & & & & & 0.617 & $0.33,1.15$ & & & 0.622 & $0.32,1.21$ \\
\hline \multicolumn{13}{|l|}{ Mother's employment } \\
\hline Unemployed & & & & & & & 0.923 & $0.49,1.75$ & & & 0.731 & $0.36,1.47$ \\
\hline \multicolumn{13}{|l|}{ Community-level factors } \\
\hline \multirow{2}{*}{\multicolumn{13}{|c|}{$\begin{array}{r}\text { Residence } \\
\text { Rural (R) }\end{array}$}} \\
\hline & & & & & & & & & & & & \\
\hline Urban & & & & & & & & & $2 \cdot 275$ & $0.55,9.48$ & $1 \cdot 195$ & $0.24,5 \cdot 89$ \\
\hline \multicolumn{13}{|l|}{ Community wealth index } \\
\hline High & & & & & & & & & 1.696 & $0.78,3.71$ & 1.565 & $0.65,3 \cdot 76$ \\
\hline \multicolumn{13}{|l|}{ Maternal education } \\
\hline Low & & & & & & & & & & & & \\
\hline High (R) & & & & & & & & & 0.936 & $0.26,3.40$ & $1 \cdot 612$ & $0.37,7.05$ \\
\hline \multicolumn{13}{|l|}{ Safe water } \\
\hline Low $(\mathrm{R})$ & & & & & & & & & & & & \\
\hline \multicolumn{13}{|l|}{ Random effects } \\
\hline Community-level variance (SE) & $\star \star * 1.311$ & 0.48 & $\star * * 1.005$ & 0.39 & ${ }^{\star \star *} 0.848$ & 0.37 & $\star \star \star \star 1.073$ & 0.43 & ${ }^{\star \star \star} 0.681$ & 0.30 & ${ }^{\star \star *} 0.796$ & 0.36 \\
\hline VPC $=\operatorname{ICC}(\%)$ & $28.50 \%$ & & $23.40 \%$ & & $20.49 \%$ & & $24.60 \%$ & & $17 \cdot 14 \%$ & & $19 \cdot 48 \%$ & \\
\hline Explained variation (i.e. PCV in \%) & Reference & & $23.34 \%$ & & $35.32 \%$ & & $18 \cdot 15 \%$ & & $48.05 \%$ & & $39.21 \%$ & \\
\hline Log likelihood & -391.56 & & $-389 \cdot 07$ & & $-351 \cdot 01$ & & -384.50 & & -385.41 & & -343.87 & \\
\hline Model fit statistics (AIC) & $787 \cdot 11$ & & $784 \cdot 15$ & & $752 \cdot 03$ & & 795.00 & & 784.82 & & 765.73 & \\
\hline
\end{tabular}


thinness, such that those in the 'rich' category had 57\% lesser odds of being thinner than those in the 'poor' category. Furthermore, wealth index had a statistically significant association with household size, such that those from richer households significantly had a lower household size. Hence, large family size, which increased the likelihood of thinness, may be a proxy for poverty. The relationship between poverty and under-nutrition, especially in low and middle-income countries has been well established $^{(34)}$. Therefore, effective interventions for thinness (under-nutrition) in these two states and Nigeria as a whole may be interventions against poverty.

The present study found that for every unit increase in age, the odds of being overweight/obese reduced by $14 \%$. The association between age and overweight/obesity may not be unconnected with the pubertal staging of the respondents. Although the pubertal stage was not significantly associated with overweight/obesity, it had a strong statistically significant association with age $(P<0 \cdot 001)$. Females were also found to have two times higher odds of being overweight/obese than males. The relationship between overweight/obesity, age and sex of school-aged children and adolescents has been similarly reported by other studies within and outside Nigeria ${ }^{(35-37)}$. Screen time (i.e. time spent with television, computers, video games and phones) of $2 \mathrm{~h}$ or more daily had two times higher odds of being overweight/obese, while the odds of being overweight/obese reduced by $45 \%$ with a unit increase in physical activity. This finding is in line with previous studies linking overweight/obesity to reducing physical activity and increasing sedentary lifestyle, of which screen time plays a major role ${ }^{(14,15,38,39)}$.

Increasing screen time has also been associated with higher consumption of snacks, which also has been reported to significantly increase the likelihood of overweight/obesity in children ${ }^{(40)}$. Exclusive breastfeeding was found to significantly reduce the odds of being overweight/obesity by as much as $54 \%$ in line with the results of previous studies ${ }^{(41-43)}$. This finding is important as it underscores the importance of exclusive breastfeeding in reducing, not only childhood under-nutrition and mortality ${ }^{(21,44)}$, but also overweight/obesity. An interesting finding was that being part of a rich household reduced the odds of overweight/obesity by $53 \%$. This is different from what previous researchers in Nigeria have reported ${ }^{(37,39)}$, but similar to the finding in the high-income countries ${ }^{(45)}$. This may be due to community-level factors which were probably not assessed in this study, since $30 \%$ of the variance in the odds for overweight/obesity in this study is attributable to community-level factors. Community-level factors such as availability, accessibility and proximity to fast-food shops and recreational facilities or programmes in communities have been shown to influence the nutritional status of children and adolescents ${ }^{(46-48)}$. Another plausible reason for this is that, by reason of exposure, the richest households in Nigeria are already adopting the lifestyle and values of the rich in developed countries where emphasis is placed on healthy food, exercises and a slim figure.

The school-aged children and adolescents living in Osun State had three times higher odds of being overweight/obese than those from Gombe State, and this may be a reflection of the higher socio-economic status and urbanisation of Osun State and the southwestern part of Nigeria compared with the northeastern part of the country where Gombe State is located ${ }^{(49)}$. In the present study, although the wealth index was not significantly different between the two states, Osun state did significantly better for almost all other indices of better socio-economic status than Gombe state, including household size, number of children in the family, family type, mother's education, father's education and mother's employment.

Comparing the findings of the present study with those from previous multi-level analyses in Nigeria is challenging. Firstly, the previous studies were undertaken for under-five children, and they also focussed on under-nutrition alone. Furthermore, no previous research effort has used multi-level modelling to understand the determinants of overweight/obesity among any group of children/adolescents in Nigeria ${ }^{(20,21,24)}$. Additionally, the reference values used in the present study are different from those used by other previous studies. Previous studies used height-for-age (for stunting) ${ }^{(20,21)}$, weight-for-age (for underweight) ${ }^{(24)}$ and weight-for-height (for wasting) ${ }^{(24)}$ reference values, which are all indicators of undernutrition. The present study used the BMI-for-age reference values, which has the advantage of measuring both under-nutrition (measured as thinness) and over-nutrition (measured as overweight and obesity) $^{(28)}$.

A limitation of this study is that the findings of this study may not be generalisable to all of Nigeria, because only two out of thirty-six states were involved in the study. Another limitation is that, as to date, there was no data about the contextual determinants of overweight/obesity among older children in Nigeria using multi-level analysis, hence making the comparison of the findings of the present study and others challenging. The cross-sectional nature of the study also makes it impossible to establish causality.

\section{Policy implications}

The findings of this study have some important policy implications. The present study observed that the community-level factors contributed significantly to the odds of under- and over-nutrition, indicating the need to explore community-based nutritional interventions for school-aged children and adolescents. There is also a need to review current interventions to assess whether/how they could be scaled-up and targeted at reducing socio-economic in-equalities, and especially poverty among households in the study location. The food systems approach of the Food and Agriculture Organization to create an enabling 
environment for improved nutrition ${ }^{(50)}$ can guide governance for improved nutrition, evidence-based policies and programmes and financial investment to facilitate changes in food systems. The findings of the present study underscore the importance of reduced physical activity and prolonged screen time in increasing the odds for overweight/obesity among the school-aged children and adolescents. There is a need, therefore, for the development of recreational, sports or games centres and programmes for children and adolescents in different communities that will increase engagement in physical activity and reduce screen time among them.

\section{Conclusion}

This study showed that Nigeria faces the challenge of a double burden of malnutrition among its school-aged and adolescents (6-19 years), with over a fifth experiencing either under-nutrition or over-nutrition. The study showed thinness and overweight/obesity among school-aged children and adolescents were strongly influenced by their communities, individual-level factors and their residence. Predictors of thinness in this study were household size and household wealth index. Overweight/obesity was significantly associated with the age, sex, exclusive breastfeeding, physical activity and household wealth index. Policymakers and stakeholders should therefore plan community-based educational programs to address, especially, socio-economic status, physical activity patterns among the children and the control of family/household size in the two Nigerian states.

\section{Acknowledgements}

Acknowledgements: The authors wish to appreciate the study participants and the study staff for their involvement and support that made this study possible. Financial support: The research work was supported by the Consortium for Advanced Research Training in Africa (CARTA). CARTA is jointly led by the African Population and Health Research Center and the University of the Witwatersrand and funded by the Carnegie Corporation of New York (Grant No G-1957145), Sida (Grant No: 54100113), Uppsala Monitoring Centre and the DELTAS Africa Initiative (Grant No: $107768 / \mathrm{Z} / 15 / \mathrm{Z}$ ). The DELTAS Africa Initiative is an independent funding scheme of the African Academy of Sciences (AAS)'s Alliance for Accelerating Excellence in Science in Africa (AESA) and supported by the New Partnership for Africa's Development Planning and Coordinating Agency (NEPAD Agency) with funding from the Wellcome Trust (UK) and the UK government. The statements made and views expressed are solely the responsibility of the Fellows. Conflict of interest: The authors declare that there is no conflict of interest. Authorship: All the authors were involved in the conceptualisation of the research idea and topic, the design of the methodology and the proposal. A.A. carried out the study as part of his PhD work, while A.F. and K.K. supervised, provided useful suggestions and the mentorship that helped to shape the study into the present form. All the authors read and approved the final version of the manuscript. Ethics of human subject participation: The study was conducted according to the guidelines of the Declaration of Helsinki, and approved by the Human Research Ethics Committee of University of the Witwatersrand (certificate No: M190514) and the ministry of health in Osun (certificate No: OSHREC/PRS/569T/155) and Gombe (certificate No: MOH/ADM/621/1/142) States. Written informed consent was obtained from all subjects/ patients.

\section{References}

1. World Health Organisation (WHO) (2017) The Double Burden of Malnutrition: Policy Brief. http://www.who.int/ nutrition/double-burden-malnutrition/en/ (accessed August 2018).

2. United Nations Children's Fund (UNICEF) (2017) Children in a Digital World. State World Child. https://www.unicef.org/ publications/files/UNICEF_SOWC_2016.pdf (accessed May 2018).

3. Popkin BM, Corvalan C \& Grummer-Strawn LM (2019) Dynamics of the double burden of malnutrition and the changing nutrition reality. Lancet 6736, 1-10.

4. Doak CM, Adair LS, Bentley M et al. (2005) The dual burden household and the nutrition transition paradox. IntJ Obes $\mathbf{2 9}$, 129-136.

5. Davison K, Birch L, Davison KK et al. (2001) Childhood overweight: a contextual model and recommendations for future research. Obes Rev 2, 159-171.

6. Bronfenbrenner U (1986) Ecology of the family as a context for human development: research perspectives. Dev Psychol 22, 723-742.

7. Bronfenbrenner U \& Morris PA (2006) The bioecological model of human development. In Child and Adolescent Development an Advance Course, pp. 793-828 [W Damon and RM Lerner, editors]. New York: Wiley.

8. Ettekal A \& Mahoney JL (2017) Ecological systems theory. In SAGE Encyclopedia of Out-of-School Learning, pp. 239-241 [K Peppler, editor]. Thousand Oaks: SAGE Publications, Inc.

9. Walker JL, Ardouin S \& Burrows T (2017) The validity of dietary assessment methods to accurately measure energy intake in children and adolescents who are overweight or obese: a systematic review. Eur J Clin Nutr 72(2), 185-197.

10. Esimai OA \& Ojofeitimi E (2015) Nutrition and health status of adolescents in a private secondary school in Port Harcourt. Health Sci J 9, 1-5.

11. Adeomi AA, Adeoye OA, Asekun-Olarinmoye EO et al. (2014) Evaluation of the Effectiveness of Peer Education in Improving HIV Knowledge, Attitude, and Sexual Behaviours among in-School Adolescents in Osun State, Nigeria. http:// www.hindawi.com/journals/art/2014/131756/ (accessed April 2015).

12. Achunam Simeon N (2015) Assessment of nutritional status among primary school pupils in rural and urban areas of Anambra state. Eur J Prev Med 3, 34.

13. Senbanjo IO, Oshikoya KA, Senbanjo IO et al. (2010) Physical activity and body mass index of school children and adolescents in Abeokuta, Southwest Nigeria. World $J$ Pediatr 6, 217-222. 
14. Oyeyemi A, Ishaku CM, Oyekola J et al. (2016) Patterns and associated factors of physical activity among adolescents in Nigeria. PLoS One 11, 1-16.

15. Lateef OJ, Njogu E, Kiplamai F et al. (2016) Determinants of overweight and obesity among adolescent students in public secondary schools in Kwara State, Nigeria. Curr Res Nutr Food Sci J 4, 96-106.

16. Goon DT, Toriola AL, Uever J et al. (2017) Growth status and menarcheal age among adolescent school girls in Wannune, Benue state, Nigeria. BMC Pediatr 10, 60.

17. Jaja T \& Alex Hart B (2016) Prevalence of overall and central obesity among adolescent girls in Port Harcourt: a comparison of different methods. Orig Niger J Paediatr 43, 209-214.

18. Oduwole AA, Ladapo TA, Fajolu IB et al. (2012) Obesity and elevated blood pressure among adolescents in Lagos, Nigeria: a cross-sectional study. BMC Public Health 12, 1.

19. Merlo J, Chaix B, Ohlsson H et al. (2006) A brief conceptual tutorial of multilevel analysis in social epidemiology: using measures of clustering in multilevel logistic regression to investigate contextual phenomena. J Epidemiol Commun Health 60, 290-297.

20. Adekanmbi VT, Kayode GA \& Uthman OA (2013) Individual and contextual factors associated with childhood stunting in Nigeria: a multilevel analysis. Matern Child Nutr 9, 244-259.

21. Uthman OA (2009) A multilevel analysis of individual and community effect on chronic childhood malnutrition in rural Nigeria. J Trop Pediatr 55, 109-115.

22. Dean A, Arner T, Sunki G et al. (2011) Epi InfoTM, a Database and Statistics Program for Public Health Professionals. Atlanta, GA: CDC.

23. National Population Commission \& ICF International (2014) Nigeria Demographic and Health Survey 2013. Abuja and Rockville, MD: NPC and ICF International.

24. Akombi BJ, Agho KE, Merom D et al. (2017) Multilevel analysis of factors associated with wasting and underweight among children under-5 years in Nigeria. Nutrients 9, 44.

25. Harris PA, Taylor R, Thielke R et al. (2009) Research electronic data capture (REDCap) - a metadata-driven methodology and workflow process for providing translational research informatics support. J Biomed Inf 42, 377-381.

26. International Society for the Advancement of Kinanthropometry (2001) International Standards for Anthropometric Assessment. https://www.researchgate. net/publication/333585249_Standards_for_Anthropometry_ Assessment (accessed March 2019).

27. Kowalski KC (2004) The Physical Activity Questionnaire for Older Children (PAQ-C) and Adolescents (PAQ-A) Manual. Saskatoon: College of Kinesiology University of Saskatchewan, 11-15. https://www.researchgate.net/ publication/228441462_The_Physical_Activity_Questionnaire_ for_Older_Children_PAQ-C_and_Adolescents_PAQ-A_Manual (accessed March 2019).

28. de Onis M, Onyango AW, Borghi E et al. (2007) Development of a WHO growth reference for school-aged children and adolescents. Bull World Health Organ 85, 660-667.

29. Emmanuel M \& Bokor B (2020) StatPearls. Treasure Island, FL: StatPearls Publishing. https://www.ncbi.nlm.nih.gov/ books/NBK470280/ (accessed March 2021).

30. StataCorp. (2017) Stata Statistical Software: Release 15. College Station, TX: StataCorp. LLC.

31. National Population Commission \& Federal Republic of Abuja Nigeria (2018) Nigeria Demographic and Health Survey. https://dhsprogram.com/publications/publicationfr359-dhs-final-reports.cfm (accessed October 2020).

32. Boco AG (2010) Individual and Community-level Effects on Child Mortality: An Analysis of 28 Demographic and Health Surveys in Sub-Saharan Africa. http://www.measuredhs. com/pubs/pdf/WP73/WP73.pdf (accessed February 2021).
33. Abu HO, Oguejiofor EO, Gbarage MT et al. (2016) Feeding practices and determinants of the nutritional status of pupils in a public primary school in Aladinma. Int J Clin Nutr $\mathbf{4}$, 12-18.

34. Petrou S \& Kupek E (2010) Poverty and childhood undernutrition in developing countries: a multi-national cohort study. Soc Sci Med 71, 1366-1373.

35. Asiegbu U, Asiegbu O, Onyire B et al. (2017) Assessment of gross malnutrition among primary school children using body mass index as an assessment tool in Abakaliki metropolis of Ebonyi state, South-East Nigeria. Niger J Clin Pract 20, 693-699.

36. Modjadji P \& Madiba S (2019) The double burden of malnutrition in a rural health and demographic surveillance system site in South Africa: a study of primary schoolchildren and their mothers. BMC Public Health 2019, 1-11.

37. Olasinde Y, Adesiyun O, Olaosebikan R et al. (2020) Nutritional status of primary school children in Ilorin-West LGA, Kwara state, Nigeria. J Community Med Prim Health Care 32, 103-115.

38. Adeomi A, Adeoye O, Bamidele J et al. (2015) Pattern and determinants of the weight status of school-age children from rural and urban communities of Osun state, Nigeria: a comparative study. J Med Nutr Nutraceut 4, 107-114.

39. Omisore AG, Omisore B, Abioye-Kuteyi EA et al. (2018) Inschool adolescents' weight status and blood pressure profile in South-western Nigeria: urban-rural comparison. $B M C$ Obes 5, 2.

40. Adesina AF, Peterside O, Anochie I et al. (2012) Weight status of adolescents in secondary schools in Port Harcourt using body mass index (BMI). Ital J Pediatr 38, 1-7.

41. Koletzko B, Kries V, Monasterolo RC et al. (2009) Can infant feeding choices modulate later obesity risk? Am J Clin Nutr 89, 1502-1508.

42. World Health Organization (2014) Exclusive Breastfeeding to Reduce the Risk of Childhood Overweight and Obesity. https://www.who.int/elena/bbc/breastfeeding_childhood_ obesity/en/ (accessed April 2021).

43. Weng SF, Redsell SA, Swift JA et al. (2012) Systematic review and meta-analyses of risk factors for childhood overweight identifiable during infancy. Arch Dis Child 97, 1019-1026.

44. Adedini SA, Odimegwu C, Imasiku ENS et al. (2014) Regional variations in infant and child mortality in Nigeria: a multilevel analysis child mortality in Nigeria. J Biosoc Sci 47, 165-187.

45. Templin T, Hashiguchi TCO, Thomson B et al. (2019) The overweight and obesity transition from the wealthy to the poor in low- and middle- income countries: a survey of household data from 103 countries. PLoS Med 16, 1-15.

46. An R, Shen J, Yang Q et al. (2019) Impact of built environment on physical activity and obesity among children and adolescents in China: a narrative systematic review. J Sport Health Sci 8, 153-169.

47. Wolch J, Jerrett M, Reynolds K et al. (2011) Childhood obesity and proximity to urban parks and recreational resources: a longitudinal cohort study. Health Place 17, 207-214.

48. Otterbach S, Oskorouchi HR, Rogan M et al. (2021) Using Google data to measure the role of big food and fast food in South Africa's obesity epidemic. World Dev 140, 105368.

49. Federal Ministry of Health (FMoH), Department of Public Health \& National AIDS/STI Control Programme (2010) National HIV Sero-Prevalence Sentinel Survey. Tech. Rep. http://www.nigeria-aids.org/documents/2010_National HIVSeroPrevalenceSentinelSurvey.pdf (accessed April 2015).

50. Food and Agriculture Organization (2020) Enabling Environment for Improved Nutrition. https://www.fao.org/ nutrition/policies-programmes/enabling-environment-forimproved-nutrition/en/ (accessed November 2021). 